\title{
Museu do Tropeiro de Castro: uma discussão sobre a atividade tropeira e o patrimônio cultural no Paraná
}

\author{
Tropeiro's Museum of Castro: a discussion about the muleteers activity and \\ cultural heritage in Paraná State
}

\author{
Milena Santos MayeR ${ }^{A}$ \\ FABiana Lopes dA CUNHA ${ }^{\mathrm{B}}$
}

\begin{abstract}
${ }^{\text {a }}$ Doutoranda na Universidade Estadual de São Paulo (Unesp), campus Assis, mestra em Ciências Sociais Aplicadas pela instituição Universidade Estadual de Ponta Grossa (UEPG).

E-mail: milenasmayer@gmail.com
\end{abstract}
${ }^{\text {b }}$ Professora na Universidade Estadual de São Paulo (Unesp), campus Ourinhos, doutora em História Social pela Universidade de São Paulo (USP), com pós-doutorado pelo King’s College London.
E-mail: fabiana.cunha@unesp.br

\begin{abstract}
O presente texto tem por objetivo historicizar a criação do Museu do Tropeiro e compreender a institucionalização de uma memória e de uma narrativa. Localizado no município de Castro, estado do Paraná, trata-se de um museu público municipal inaugurado em janeiro de 1977, idealizado por uma professora castrense que o dirigiu durante aproximadamente 30 anos. A instituição tem por objetivo principal preservar e divulgar a história do tropeirismo de muares no Sul do Brasil. O texto expõe uma breve apresentação sobre o museu, seu contexto de fundação e seu desenvolvimento. Traz ainda um levantamento da historiografia brasileira sobre o comércio de muares no Brasil meridional. Os caminhos, definidos no século XVIII, estabeleceram-se a partir do relevo, seguindo os vales dos rios, pelas trilhas indígenas e principalmente pela procura dos campos com fartura em pastagens. No decorrer destas rotas, surgiram paradas estratégicas que se transformaram em povoados graças ao fluxo desses tropeiros. Os locais de pousos das tropas, pontos de descanso e pernoite, foram se tornando pontos de reabastecimento, de invernada e até de compra e venda de animais. Era preciso suprir as necessidades dos tropeiros através do plantio de roças e estabelecimentos comerciais os quais geraram núcleos de povoamento, como é o caso do município de Castro. O texto apresenta, portanto, a problematização e as relações estabelecidas entre a historiografia, o conceito de patrimônio cultural e o conceito de museu.
\end{abstract}

Palavras-chave: patrimônio cultural, tropeirismo, museu, Castro, Paraná.

This paper seeks to historicize the creation of the Museu do Tropeiro and to understand the institutionalization of a memory and a narrative. Located in the municipality of Castro, state of Paraná, Brazil, it is a public municipal museum inaugurated in January 1977, idealized by a local teacher, who managed it for approximately 30 years. The main purpose of the institution is to preserve and disseminate the history of tropeirismo of mules in the South of Brazil. The text shows a brief presentation about the museum, its context of foundation and its development. It also presents a survey of the Brazilian historiography on the mule trade in southern Brazil. The paths, defined in the eighteenth century, were established based on the relief, following the valleys of the rivers, the indigenous trails and mainly by the search of the fields with abundance in pastures. In the course of these routes, strategic stops emerged, becoming villages due to the flow of these tropeiros. The landing sites of the troops, rest points and overnight were becoming points of refueling, wintering and even buying and selling of animals. It was necessary to supply the needs of the tropeiros by plantations and commercial establishments, which generated nuclei of population, such as the case of the municipality of Castro. This text presents, therefore, the problematization and the relations established among the historiography, the concept of cultural patrimony and the concept of museum.

Keywords: cultural heritage, tropeirismo, museum, Castro, Paraná. 


\section{INTRODUÇÃO}

Os museus são casas que guardam e apresentam sonhos, sentimentos, pensamentos e intuições que ganham corpo através de imagens, cores, sons e formas. Os museus são pontes, portas e janelas que ligam e desligam mundos, tempos, culturas e pessoas diferentes. Os museus são conceitos e práticas em metamorfose. (IBRAM, 2013)

O trecho citado acima constava no portal eletrônico do Instituto Brasileiro de Museus (Ibram ${ }^{1}$ ), atualmente este texto foi substituído. Contudo, essa sensível definição pode ser encontrada em diversas publicações sobre museus no Brasil, e novamente é citada no início deste texto com o intuito de apresentar ao leitor a concepção de museu que a autora acredita, bem como provocar uma reflexão sobre estas instituições.

Embora a poética conceituação corresponda aos anseios da autora e talvez de grande parte dos profissionais, pesquisadores e entusiastas de museus, é importante trazer à tona a definição ${ }^{2}$ instituída pela Lei n ${ }^{\circ} 11.904$, de 14 de janeiro de 2009, que criou o Estatuto dos Museus no Brasil:

\footnotetext{
Consideram-se museus, para os efeitos desta Lei, as instituições sem fins lucrativos que conservam, investigam, comunicam, interpretam e expõem, para fins de preservação, estudo, pesquisa, educação, contemplação e turismo, conjuntos e coleções de valor histórico, artístico, científico, técnico ou de qualquer outra natureza cultural, abertas ao público, a serviço da sociedade e de seu desenvolvimento. (BRASIL, 2009)
}

Por conseguinte, de maneira objetiva e burocrática, podemos afirmar que os museus são instituições permanentes sem fins lucrativos, a serviço da sociedade e que atuam através de pesquisa, conservação e comunicação de um determinado patrimônio cultural, que pode ser material ou imaterial. No entanto, os museus "nascem" muito antes das organizações que atualmente os tutelam ou os regulamentam. A história dos museus é marcada pela própria etimologia da palavra mouseion: "pequena colina, lugar das Musas" (POULOT, 2013, p. 15). As musas eram seres mitológicos, filhas de Mnemosine, deusa da memória, e de Zeus, o pai de todos os deuses, portanto, trata-se de um mito fundador que sugere a união entre poder e memória.

1 Acesso em: 11 mar. 2019.

2 Esta acepção é fundamentada na definição do Conselho Internacional de Museus - Icom.
A origem dos museus remonta a antiguidade, mas é a partir da prática do colecionismo e dos gabinetes de curiosidades que podemos vislumbrar o princípio dessas instituições.

Sobre as origens das coleções podemos destacar os objetos conquistados através das guerras, os tesouros reunidos e conservados pelos príncipes, as coleções que sugeriam ascensão social e os conjuntos de objetos sagrados, como as relíquias, por exemplo (POMIAN, 1984). Algumas dessas coleções "serviam como estímulo à curiosidade e à pesquisa, e outras visavam unicamente ao estímulo emocional e estética" (HORTA, 1987, p. 160). Esta prática de reunião de artefatos - ou então, a história dos museus - é complexa e temos ciência de suas especificidades, entretanto, considerando os limites e a proposta deste texto, sugerimos que ela pode ser apresentada em três momentos: primeiro no período da Antiguidade Clássica, quando eram reunidas coleções de arte em templos gregos e romanos; um segundo momento seria o período do Renascimento, no qual foram criados os chamados gabinetes de curiosidades, com coleções de objetos raros ou peculiares, como as coleções dos príncipes; já o terceiro momento na história destes espaços distingue-se a partir dos ideais do Iluminismo, quando os museus europeus foram se modificando, transformando-se em locais de pesquisas e em instituições públicas (BREFE, 1998; FIGUEIREDO; VIDAL, 2013; POULOT, 2013).

A partir do "Século das Luzes", parte da sociedade, como os burgueses, por exemplo, começam a almejar o acesso à arte e à ciência dando "origem ao museu moderno, com suas funções de pesquisa, educação, valorização do racionalismo, método e classificação" (POULOT, 2013, p. 63). Segundo Dominique Poulot, é a partir do século 18 que são criados diversos tipos de museus no mundo todo, que correspondem aos valores e narrativas de seus Estados de origem.

O nacionalismo do século seguinte favorece significativamente a expansão dos museus, com a criação de novas instituições para além do continente europeu, contribuindo também para o fortalecimento dos museus já existentes. Estas instituições ganham espaço neste período exatamente por se constituírem como um local de sacralização da memória e das "conquistas" de uma nação.

O século 19 é apontado como a "Era dos Museus", segundo Poulot. Em relação ao público, é possível observar a preocupação em permitir o acesso e, portanto, desenvolver sistemas de organização das exposições e das coleções. Entretanto, "os verdadeiros usuários dos museus continuam sendo os studiosi e os artistas, que se beneficiam sempre em condições privilegiadas" (POULOT, 2013, p. 63). 
O historiador Ulpiano Bezerra de Meneses (2013) escreve que no continente americano a origem é um pouco diversa. Nos Estados Unidos, por exemplo, entre os anos 1740 e 1870, há, certamente, a influência do iluminismo europeu, entretanto há também a presença dos ideais republicanos, o crescimento da classe média e o início da profissionalização na ciência. "Educação popular e pesquisa acadêmica são eixos que o compromisso americano desenvolve a partir de museus complexos, basicamente modelados como museus de História Natural, aos quais também se integra a atuação de sociedades históricas e arquivos" (MENESES, 2013, p. 22). No Brasil ${ }^{3}$, o autor lembra que "o modelo oitocentista é, também, o do museu de História Natural, no qual se insere organicamente a Antropologia e, o como um enclave evocativo e celebrativo, a História". (MENESES, 2013, p. 22). A categoria de museu histórico que aqui nos interessa aparece apenas no século 20.

\section{Museu do Tropeiro: Caminhos E CONCEPÇÕES}

A respeito das instituições nacionais no século 20 é possível enxergar uma retomada de um sentimento nacionalista que proporciona uma nova perspectiva aos espaços museológicos e ao patrimônio histórico e cultural brasileiro. Segundo Maria de Lourdes Horta, as coleções brasileiras foram "institucionalizadas nos 'grandes museus nacionais' durante a década de 30, época de perfil político-nacionalista exacerbado e que coincide com a criação do SPHAN"” (HORTA, 1987, p. 160).

3 Em 1818, 10 anos após da vinda da família real, cria-se o Museu Real com o objetivo de propagar os conhecimentos das ciências naturais no Reino do Brasil. Ainda no século 19 são criados espaços como: Museu do Instituto Histórico e Geográfico Brasileiro (1838), Museu do Exército (1864), Museu da Marinha (1868), Museu Paraense Emilio Goelgi (1871), Museu Paranaense (1876) e o Museu Paulista (1895).

4 Serviço do Patrimônio Histórico e Artístico Nacional criado pelo decreto-lei $\mathrm{n}^{\circ} 25$, de 30 de novembro de 1937, hoje Iphan - Instituto do Patrimônio Histórico Artístico Nacional, é então responsável pela identificação, documentação e promoção do patrimônio cultural brasileiro. O órgão deveria organizar, fiscalizar e proteger os bens móveis e imóveis considerados exemplares de notável valor histórico, artístico, arqueológico ou bibliográfico.
Posteriormente à publicação do Decreto-Lei no 25, de 30 de novembro de 1937, o Serviço de Patrimônio Histórico Artísitico Nacional dedicou-se principalmente à preservação dos bens imóveis dos Séculos 16, 17, e 18, prioritariamente de arquitetura religiosa (FONSECA, 2017, p. 116). Entretanto, a letra da lei previa a proteção e a criação de instituições museais, como podemos observar no artigo 24:

A União manterá para conservação e exposição de obras históricas e artísticas de sua propriedade, além do Museu Histórico Nacional e do Museu Nacional de Belas Artes, tantos outros museus nacionais quantos se tornarem necessários, devendo, outrossim, providenciar no sentido de favorecer a instituição de museus estaduais e municipais com finalidades similares. (BRASIL, 1937)

Segundo Ana Maria Alves Machado, (2013) a relação dos museus e de outras instituições culturais com o SPHAN teve como principal articulador o seu diretor Rodrigo de Melo e Franco, que esteve à frente do órgão de 1936 até 1967. O nacionalismo dos anos 1930 marcariam a missão política das instituições museais em busca da construção e consolidação da nação brasileira, "essa mentalidade específica de organização e preservação da história pátria será a mesma que prevalecerá como tônica determinante do modelo de formatação da história de diversas localidades, através dos museus municipais" (MACHADO, 2013, p. 154).

O museu público municipal da cidade de Castro começa a tomar forma a partir do ano de 1975, momento em que o pensamento museal proposto pelo SPHAN sofre mudanças, pois a partir da década de 1970 “os museus são utilizados como instrumentos de veiculação de discursos oficiais, com tendências a efetivação do ideal do regime militar" (MACHADO, 2013, p. 154). Todavia, internacionalmente esta mesma década é caracterizada pela Nova Museologia, principalmente com a discussão da mesa-redonda, organizada pela Unesco, que ocorreu na cidade de Santiago, Chile, em 1972. Ocasião em que este campo do conhecimento, a museologia, se propõe a pensar a diversidade cultural, a defesa do patrimônio das minorias étnicas e a integração dos museus com as comunidades locais. É nesse contexto que inicia a trajetória do Museu do Tropeiro.

Aos vinte e hum dias do mês de janeiro de mil novecentos e setenta e sete, centésimo vigésimo ano da elevação da cidade de Castro à categoria de cidade, centésimo qüinquagésimo 
quinto ano da Independência do Brasil e ano da Proclamação da República foi inaugurado oficialmente, na presença das excelentíssimas autoridades e do público abaixo assinados o Museu do Tropeiro, com o objetivo de evocar aquela figura histórica do Brasil Colônia, dos séculos XVIII e XIX que tanto contribuiu para a formação da Santana do Iapó, hoje cidade de Castro, bem como de muitas outras cidades nas Províncias, hoje Estados do Rio Grande do Sul, Santa Catarina, Paraná e São Paulo. (MUSEU DO TROPEIRO, 1977, p. 1)

A literatura consultada expõe que há um incentivo à criação de museus históricos municipais, além do mais, outros museus foram criados neste mesmo período no Paraná. Entretanto, em Castro há uma característica peculiar, optou-se por um museu histórico temático, como podemos observar na ata de inauguração do mesmo. O próprio nome escolhido indica seu objetivo, bem como no trecho citado acima é possível verificar que o compromisso da instituição é especificamente com a história da origem do município e indica o provável alcance regional deste museu, posto que se trata de um tema comum a outras localidades brasileiras.

Pesquisando nos arquivos institucionais do Museu do Tropeiro percebemos que a criação e a consolidação desse museu não se dão apenas pelo anseio de uma só pessoa, tarefa inexequível, porém é inegável a participação e a dedicação fundamental de uma mulher: a professora Judith Carneiro de Mello ${ }^{5}$. Este museu é intimamente vinculado à sua idealizadora, que cumpriu

5 Professora Judith Carneiro de Mello nasceu em Castro, no Paraná, em 11 de abril de 1923, filha de Vespasiano Carneiro de Mello, empresário e político, e de Maria da Conceição Bueno Barbosa Carneiro de Mello. Judith era integrante de uma das mais antigas e conhecidas famílias do município de Castro, Paraná. Estudou nos Colégios São José e Diocesano Santa Cruz da cidade natal, seguindo depois para Curitiba onde formou-se normalista em 1942 e em seguida foi nomeada para o Grupo Escolar Vicente Machado. No ano de 1949, retorna para Curitiba para cursar a Escola Superior de Educação Física, lecionando por três anos no Grupo Escolar da Mercês na capital do Estado. Lecionou também no município de Piraí do Sul no Grupo Escolar "Leandro da Costa", na Escola Normal Regional e no Ginásio Jorge Queiroz. Transferida em 1954 para Rolândia, também no estado do Paraná, trabalhou no Ginásio Estadual e na Escola Normal Regional. Em 1964 retornou para sua cidade natal e lecionou na Escola Normal Amanda C. de Mello e mais tarde foi Diretora do Ginásio Estadual de Castro, hoje Colégio Estadual Major Vespasiano Carneiro de Mello. Aposentou-se da função de professora no ano de 1983, após trinta anos dedicados à educação. a função de diretora por aproximadamente 30 anos. Esta informação consta também na Ata de Inauguração do Museu do Tropeiro:

A ideia de criação de um museu histórico na cidade de Castro é um sonho muito antigo e um sonho de longos anos da professora Judith Carneiro de Mello, a cujo o empenho e dinamismo hoje é inaugurado um de seus anelos, em beneficio, não somente da gente de sua terra natal, mas de todos que por aqui passarem e tiverem o privilégio de visitar o Museu do Tropeiro. (MUSEU DO TROPEIRO, 1977, p. 1)

A figura da professora Judith aparece constantemente em grande parte dos documentos produzidos pela ou sobre a instituição, assim como está na memória e na fala dos funcionários e de muitos visitantes e pesquisadores que tivemos a oportunidade de conhecer ${ }^{6}$.

Na gestão do advogado Lauro Lopes, então prefeito municipal, Judith encontrou apoio para concretizar o seu projeto. O primeiro passo burocrático foi a publicação da declaração de utilidade pública de um imóvel, para fins de desapropriação, em 16 de maio de 1975. Logo em seguida a edificação foi adquirida e restaurada com recursos da Prefeitura Municipal de Castro. No ano subsequente pelo Decreto Municipal n ${ }^{\circ} 71 / 76$ do dia 1 de dezembro de 1976, foi oficialmente criado o Museu do Tropeiro, inaugurado no mês seguinte em 21 de janeiro de 1977.

Sobre a sede é importante destacar que se trata de uma casa construída no final do século XVIII com características de arquitetura colonial, "apresenta aberturas com requadros em madeira, vergas encurvadas, janelas de peitoril, folhas externas em sistema de guilhotina, divididas em quadrículos, postigos internos em calha e portas com bandeiras". (LYRA, 2006, p. 80). As obras de restauração foram executadas com o acompanhamento da Divisão do Patrimônio Histórico e Artístico do Paraná, segundo projeto do arquiteto Sérgio Todeschini Alves. No mesmo ano da inauguração foi instaurado o processo de tombamento do imóvel que, desde 1978, está sob proteção do estado do Paraná.

Mas por qual razão surge a proposta de um museu temático? Como o "tropeiro" tornou-se principal elemento para a política de preservação do patrimônio cultural do município?

6 Judith faleceu no ano de 2007, tendo a pesquisadora iniciado suas atividades profissionais no Museu do Tropeiro no ano 2012. 
Já na fase de pesquisas, quando a ideia era a da criação do Museu da História de Castro, recebemos a visita do: eminente Professor Dr. Newton Carneiro, membro do Conselho do Patrimônio Histórico e Artístico Nacional, pessoa conhecida de todos os paranaenses, pela sua cultura invulgar e por ser a autoridade absoluta que é em questões de História. Mostrou-se vivamente interessado, transmitindo-nos o seu entusiasmo e a certeza de que a instalação de um "MUSEU DO TROPEIRO", sobre estar, mais condicionada à história da cidade, seria a realização inédita no Brasil. Disse mais, o ilustre historiador, que não via melhor abrigo para um acervo do tropeiro do que esta casa, e que deveríamos entrar em contato com o IPHAN. (MUSEU DO TROPEIRO, 1980)

Além deste trecho presente em um boletim institucional, Judith revela, em entrevista gravada e transcrita, o diálogo com o historiador Newton Carneiro

A gente não ouve mais as histórias como eu ouvia de minha avó, e como o povo vivia diferente. Estou vendo um descaso pela nossa história, nossa origem. Então, eu fico muito grata que o senhor me dê essa orientação. Eu só peço uma coisa: que o senhor me ajude a fazer esse museu. Ele falou: "Ah! Mas eu estou muito satisfeito [...] porque Castro é a cidade depositária de toda a história do Paraná”. Eu fui vendo que toda aquela história que meu pai contava, do caboclo de Castro, estava dentro daquilo que eu procurava $[. .$.$] em$ dois meses eu pus todo aquele acervo do museu lá dentro, graças às amizades do meu pai. No interior do município, aonde eu chegava, eles diziam: "não posso ir, mas a senhora pode levar o que achar que pode servir para o seu museu. (ASSOCIAÇÃO DE AMIGOS DO MUSEU DO TROPEIRO, 2013, p. 26)

A história do tropeiro no Paraná é, portanto, a história de uma estrutura agrária, o que a historiografia tradicional paranaense denominou de "sociedade campeira". A economia era baseada na subsistência e nas atividades pecuárias. Saint-Hilaire, em sua viagem pela região dos Campos Gerais, em 1822, descreveu os hábitos e as caraterísticas que encontrou durante o caminho. Segundo o viajante, os homens desta região estavam "sempre a cavalo e andavam quase sempre a galope, levando um laço de couro amarrado à sela, que é de um tipo especial denominado lombilho" (SAINT-HILAIRE, 1995, p. 18).

Não se deve pensar, porém, que os habitantes dos Campos Gerais permaneçam sempre em sua região. Homens de todas as classes, operários, agricultores, no momento em que ganham algum dinheiro, partem para o sul, onde compram burros bravos para revendê-los em sua própria terra ou em Sorocaba. (SAINT-HILAIRE, 1995, p. 19)

O tropeiro, por definição, é aquele que conduz uma tropa, principalmente de equídeos; aquele que conduz bestas de carga ou manadas de gado, cavalos e bois; aquele que negocia gado; um empresário de transportes. Encontram-se tropas e tropeiros em grande parte do território povoado durante o período colonial brasileiro e após a independência, entretanto, é ao comércio de muares no Brasil meridional, denominado pelos estudiosos e interessados, como tropeirismo, que se dedica o Museu do Tropeiro de Castro.

Pesquisadores dessa temática argumentam que a expansão territorial do sul do país se dá principalmente a partir desta atividade econômica. $\mathrm{O}$ caminho mais conhecido e que serve como referência para esta atividade é o chamado Caminho do Viamão, trilhado pela primeira vez por Cristóvão Pereira de Abreu entre os anos de 1731 e 1732, conduzindo aproximadamente 3000 mulas durante esta tropeada (GOULART, 1961, p. 37). Mais tarde, com o estabelecimento da feira anual de Sorocaba, sabe-se que o tráfego de tropas e tropeiros era intenso, atravessando as regiões que correspondem hoje ao estado do Rio Grande do Sul, Santa Catarina e o Paraná até chegar ao estado de São Paulo. Sérgio Buarque de Holanda afirma também que é a partir de 1730, "com a abertura do caminho por terra que de Curitiba ia dar às campinas do Viamão e à colônia do Sacramento, é que o cavalo começa a ter lugar no ritmo ordinário da vida paulista" (HOLANDA, 1975, p. 154). Na obra "Caminhos e fronteiras" há um trecho intitulado "Do peão ao tropeiro", no qual o historiador escreve sobre a falta dos animais de transporte e a condição das estradas na região de São Paulo. "O paulista se locomovia a pé, pois possuir cavalgaduras era um luxo" (HOLANDA, 1975, p. 131).

Partindo de inventários post mortem e outras documentações de registro de impostos, o autor destaca que "a partir de 1733, ou pouco depois, é que começa a avolumar-se o número de bestas muares vindas do Sul, geralmente de passagem para as minas" (HOLANDA, 1975, p. 155).

Com as feiras de animais de Sorocaba, assinala-se, distintamente, uma significativa etapa na evolução da economia e também da sociedade paulista. Os grossos cabedais que nelas se apuram, tendem a suscitar uma nova mentalidade na população. O tropeiro é o sucessor direto do sertanista 
e o precursor, em muitos pontos, do grande fazendeiro. A transição faz-se assim sem violência. O espírito de aventura, que admite e quase exige agressividade ou mesmo a fraude, encaminha-se, aos poucos, para uma ação mais disciplinadora. (HOLANDA 1975, p. 158)

O historiador não utiliza o termo "tropeirismo", entretanto, é interessante observar como ele descreve essa atividade e os sujeitos envolvidos. A afirmação de que há uma mudança de mentalidade e as características que o autor descreve no decorrer do texto corroboram com muitos discursos encontrados sobre a temática.

Há na figura no tropeiro paulista, como na do curitibano, do rio-grandense, do correntino, uma dignidade sobranceira e senhoril, aquela mesma dignidade que os antigos costumavam atribuir ao ócio mais do que ao negócio, muitos dos seus traços revelam nele a herança ainda bem viva, e tempos passados, inconciliável com a moral capitalista. A dispensa muito frequente de outra garantia nas transações, além da palavra empenhada, que se atesta no gesto simbólico de trocar o fio de barba em sinal de assentimento, casa-se antes com a noção feudal de lealdade do que com o conceito moderno de honestidade comercial. [...] O amor ao luxo e aos prazeres domina, em pouco tempo, esses indivíduos rústicos, que ajaezam suas cavalgaduras com ricos arreios de metal precioso ou que timbram em gastar fortunas nos cabarés, nos jogos, nos teatros. [...] A ostentação de capacidade financeira vale aqui quase por uma demonstração de força física. Ao menos nisto, e também na aptidão para enfrentar uma vida cheia de riscos e rigores, o tropeiro ainda pertence à família bandeirante. (HOLANDA, 1975, p. 159)

Quem visita a exposição do Museu do Tropeiro pode construir pontes e analogias entre o acervo, a narrativa da exposição e este trecho citado acima. Inclusive, durante um longo período, esteve em exposição o "Código do Tropeiro", que reforçava principalmente a questão da honestidade e da cordialidade destes negociantes ${ }^{7}$. A ostentação financeira é perceptível através das peças de prata e alpaca, bem como os móveis e louças da "casa do tropeiro".

7 "Competia ao tropeiro: Não deixar porteira aberta; respeitar a propriedade alheia; saudar a todos que encontrasse em caminho; nunca chegar à casa de alguém pelo lado da cozinha; respeitar as mulheres; ser leal aos companheiros; ser correto nos negócios; honrar a palavra dada" (ROMAGUERA NETTO, 2002).
No que diz respeito às rotas percorridas por estes tropeiros, definidas no século 18, foram determinadas a partir do relevo, seguindo os vales dos rios, mas também pelas trilhas indígenas existentes na região e principalmente pela procura dos campos com fartura em pastagens. Ao longo do caminho surgiram paradas que se transformaram em povoados graças ao fluxo desses tropeiros. Os locais de pousos das tropas foram se tornando pontos de reabastecimento, de invernada e até de comércio de muares. Era preciso suprir as necessidades dos tropeiros através do plantio de roças e estabelecimentos comerciais os quais geraram núcleos de povoamento, que foram expandindo até tornarem-se cidades.

Entregues à vida campeira, continuidade dos grupos paulistas de que descendiam historicamente, vivendo numa região que se constituiu em “zona de passagem”, entre o Rio Grande do Sul e São Paulo, no período das tropas, de que participaram intensamente, estabelecendo um contínuo contato com os paulistas e rio-grandenses, os habitantes dos Campos Gerais tinham, sobretudo, costumes de gaúchos. (BALHANA; MACHADO; 1968, p. 38)

Entre o século 18 e meados do 19, Castro se estabelece como o centro administrativo de toda essa região denominada Campos Gerais ${ }^{8}$. Pelo regime de sesmarias, a Coroa Portuguesa concedia grandes extensões de terras às famílias que desejassem fixar moradia. $\mathrm{O}$ primeiro requerimento desse caráter, feito por Pedro Taques de Almeida, data de 19 de março de 1704. A historiografia local $^{9}$ aponta que o rio Iapó ${ }^{10}$, por sua característica de tornar-se alagado, obrigava os tropeiros a aguardar e acampar. De tal modo, o antigo Pouso do Iapó avançou para a categoria de Freguesia de Sant'Ana do Iapó no ano de 1774, quando foi construída a primeira capela. A ascensão da Vila Nova de Castro ocorreu em 20 de janeiro de 1789, em homenagem a Martinho Mello e Castro, então Secretário dos Negócios Ultramarinos

8 Geograficamente Reinhard Maack (1981) define Campos Gerais como uma região de aproximadamente 19.060 km²: "utilizados predominantemente para a criação intensiva de gado bovino, entende-se desde a fronteira com o Estado de Santa Catarina até o limite com o Estado de São Paulo" (MAAK, 1991, p. 256).

9 José Pedro Novaes (1972); Oney Barbosa Borba (1986).

10 O Rio Iapó nasce no município de Piraí do Sul, corta o perímetro urbano de Castro e deságua no Rio Tibagi, no município de mesmo nome. 
de Portugal. A Vila Nova de Castro foi elevada à categoria de cidade em 21 de janeiro de 1857, portanto a primeira cidade instituída após a emancipação da Província do Paraná (1853). De posse destas informações e do conhecimento de que os caminhos vindos do sul passavam por esta região, bem como amparada pela historiografia, através principalmente do historiador Newton Carneiro, Judith Carneiro de Mello organiza e institui o Museu do Tropeiro.

Compreendemos que todos aqueles que de alguma forma participavam desta atividade podem ser denominados tropeiros, e não somente os donos das tropas. Entretanto, a ideia de tropeiro a priori está atrelada ao dono do capital e muitos destes homens enriqueceram a partir desta atividade, ademais, justamente pela posição econômica, alguns tropeiros tiveram grande participação na vida política da região sul. Brasil Pinheiro Machado escreve que os grandes proprietários rurais, os que detinham grandes fortunas da província, representavam o poder político local. A partir da emancipação da Província do Paraná, em 1853, o poder local é inteiramente restituído às classes superiores locais e, especialmente, à classe dos fazendeiros dos Campos Gerais, constituindo assim uma oligarquia (BALHANA; MACHADO, 1968).

A influência e o prestígio destes comerciantes são registrados pela historiadora Cecília Westphalen, pois, segundo a autora, entre os anos 1842 e 1888 foram outorgados na região do Paraná oito títulos de nobreza, sendo seis destes títulos para tropeiros: Barão de Antonina, Barão do Tibagi, Barão dos Campos Gerais, Barão de Guarapuava (depois Visconde de Guarapuava), Barão de Guaraúna e Barão de Monte Carmelo (WESTPHALEN, 1995, p. 17).

Contudo, a estrutura agrária dessa região não é somente composta por grandes latifúndios e por ricos proprietários, mas por pequenas propriedades e trabalhadores escravizados ou livres. Os objetos que são representativos desta atividade, são também objetos comuns do cotidiano da vida rural no Brasil. A cultura material relacionada a este tema é bastante diversificada. A lida com os animais é composta por artefatos como freios, selas, pelegos, estribos, coxonilhos, chicotes, esporas; objetos de carga, como bruacas, canastras, cangalhas, jacás; objetos de indumentária, como chapéus, botas, ponchos; objetos de uso nos pousos, bancos, caldeirões, chocolateiras, talheres; objetos de uso pessoal, garruchas, facas, punhais; entre outros elementos que estão relacionados diretamente ao trabalho no campo, à viagem e ao comércio de animais.
Portanto, o acervo do Museu do Tropeiro é composto majoritariamente por esta tipologia de objetos. Como dito no início do texto, nos propomos a provocar uma reflexão acerca do patrimônio cultural institucionalizado por esta instituição. Os bens culturais, hoje tombados, eleitos patrimônio público do município de Castro, sofreram um processo de seleção pois o "espaço material dos museus é constituído social e simbolicamente pelo tenso entrecruzamento de diversas relações entre grupos étnicos, classes sociais, nações, categorias profissionais, público, colecionadores, artistas, agentes do mercado de bens culturais, agentes do Estado etc." (GONÇALVES, 2007, p. 83). Sendo assim, ponderando a função social dos museus, principalmente um museu público, nos propusemos, em uma pesquisa que ainda se encontra em andamento, historicizar e problematizar a constituição e a trajetória dessa instituição.

Se o patrimônio é interpretado como repertório fixo de tradições, condensadas em objetos, ele precisa de um palco-depósito que o contenha e o proteja, um palco-vitrine para exibi-lo. O museu é a sede cerimonial do patrimônio, o lugar em que é guardado e celebrado, onde se reproduz o regime semiótico com que os grupos hegemônicos o organizaram. Entrar em um museu não é simplesmente adentrar um edifício e olhar as obras, mas também penetrar em um sistema ritualizado de ação social. (CANCLINI, 2011, p. 169)

Os artefatos materiais, vulgarmente, são vistos apenas como produto da ação humana, entretanto, é necessário compreender que os comportamentos sociais também podem ser moldados pelos objetos. Os museus são "recursos estratégicos" para esse entendimento, pois "no museu, objetos de nosso cotidiano (mas fora desse contexto e, portanto, capazes de atrair observação) ou estranhos à vida corrente (capazes, por isso, de incorporar a minhas experiências alheias) assumem valores cognitivos, estéticos, afetivos, sígnicos" (MENESES, 2013, p. 19).

\section{TEATRO DA MEMÓRIA OU LABORATÓRIO DA HISTÓRIA?}

As especificidades de criação do Museu do Tropeiro e a maneira como ele se estabeleceu na sociedade oferecem subsídios capazes de auxiliar a instituição museal pesquisada a cumprir sua função social e assim atingir os mais diferentes públicos, bem como promover a reflexão 
para outras instituições. Ulpiano Bezerra de Meneses questionava, na década de 1990, quais as possibilidades de participação de um museu histórico na produção do conhecimento histórico. Teatro da memória ou laboratório da história? Nesse sentido, questionamos hoje qual seria a orientação do Museu do Tropeiro.

O Museu do Tropeiro tem por finalidade: - primeiro: - pesquisar e estudar os documentos, arquivos e demais registros sobre a pessoa do tropeiro e de sua influência econômica, social e cultural na área de sua atuação; segundo: - reunir os testemunhos materiais autênticos usados pelo tropeiro na sua época; - terceiro: - expor estes objetos para o conhecimento e apreciação de estudiosos e do público em geral; quarto: contribuir com a política de Turismo do Governo da Revolução de 1964, no eixo Vila Velha - Foz do Iguaçu, no plano de Turismo Cultural. (MUSEU DO TROPEIRO, 1977, p. 1)

Neste trecho da ata de inauguração observamos a intenção em tornar-se, em primeiro lugar, uma instituição de pesquisa. Esta é uma informação essencial quando tratamos de museus históricos tradicionais, principalmente os museus públicos municipais, aqueles que estão longe dos grandes centros e da Academia. Afinal, sabe-se que paira na sociedade uma ideia de que museus são depósitos de velharias. A partir da análise das fontes, documentos administrativos e publicações da instituição, percebemos o propósito da pesquisa desde a sua gênese, o que certamente influenciou diretamente na formação do arquivo documental e da biblioteca especializada da instituição, isto é, pesquisa em documentos oficiais. Contudo, ainda precisamos aprofundar, caso existam, investigações a partir dos bens culturais pertencentes à instituição. Nesse momento, podemos sugerir que as determinações das escolas metódica e positivista na produção do conhecimento histórico podem, de alguma maneira, ter influenciado esta prevalência.

De acordo com o conceito de museu exposto no início do texto, museus são locais que conservam, investigam, comunicam, interpretam e expõem determinado patrimônio de alcance histórico, artístico, científico, técnico ou de qualquer outro caráter. Para complementar esta análise a respeito do Museu do Tropeiro e a relação entre patrimônio cultural e institucionalização de uma narrativa, além do contexto de fundação, apresentamos um trecho retirado de um Boletim Informativo produzido em comemoração ao terceiro aniversário da instituição:
Castro, que representa, por força do tropeirismo, um importante elo de integração entre o norte e o sul, tem neste Museu do Tropeiro conservado suas tradições. Vai mostrar às gerações de hoje e o do futuro toda a pujança de uma era de coragem, de desbravamento, de patriotismo e de afirmação de valores pátrios. Muito, portanto, falará a posteridade este monumento. Ele a prova de um passado de trabalho, de um presente de realidades e de um futuro repleto de esperanças. Ele é o tributo de gratidão àqueles home ns obstinados que, embalados pela sua bravura, laçaram-se à magnifica aventura de abrir novos caminhos no chão da Pátria, propiciando o surgimento de novos núcleos de civilização, de novas cidades, de nossa cidade de Castro. E porque retrata este Museu a fisionomia sociológica de uma época de nossa história, a sua finalidade não é, apenas, a de guardar o acervo dos usos e costumes do tropeiro, todavia sirva ele de exemplo e estímulo para as gerações futuras, convidando à reflexão, ao estudo, e à pesquisa social e histórica. (MUSEU DO TROPEIRO, 1980)

O texto apresenta o museu como monumento. $\mathrm{O}$ termo monumento tem sua origem no latim monumentum, derivação de monere, ou seja, lembrar ou advertir. A historiadora Françoise Choay argumenta que este termo denota uma natureza afetiva, portanto "não se trata de apresentar, de dar uma informação neutra, mas de tocar, pela emoção, uma memória viva" (CHOAY, 2017, p. 18). Este aspecto é evidenciado quando citamos o depoimento da senhora Judith e sua preocupação em preservar as memórias relatadas por seu pai ou que ela testemunhara, bem como no trecho acima, quando utiliza-se a expressão "tributo de gratidão", dialogando diretamente com a definição proposta por Choay que considera monumento "tudo que for edificado por uma comunidade de indivíduos para rememorar ou fazer que outras gerações de pessoas rememorem acontecimentos, sacrificios, ritos ou crenças" (CHOAY, 2017, p. 18). Além deste aspecto, destacamos também a intenção em preservar uma história de exaltação à pátria e ao patriotismo, tão intrinsicamente vinculada à política de preservação em todo o território nacional.

Todavia, o final do texto convidando o visitante à reflexão e a pesquisa interrompem o raciocínio de imposição de uma determinada versão ou então de apenas um memorial que não apresenta questionamentos e problemáticas. Nos parece que o (a) autor (a) do texto, porta voz da instituição, reitera a posição de que os museus devem ir além do senso comum de guardiões da memória, há a preocupação com a produção do conhecimento histórico. Essa aparente incongruência aguça ainda mais o interesse na pesquisa sobre a instituição. Sabemos que o processo 
de construção do conhecimento é dinâmico e implica diversas adversidades, especialmente para o historiador que está constantemente refletindo sobre o ofício.

Jacques Le Goff (2013) escreve que é em função das necessidades contemporâneas que a história recolhe, classifica e agrupa os fatos passados. "É em função da vida que ela interroga a morte" (LE GOFF, 2013, p. 29). A função social da história pode ser definida como a organização do passado em função do presente. Neste sentido, as discussões sobre objetividade e imparcialidade na atividade do historiador é recorrente. Sobre o tema, o autor distingue os dois termos, salientando que a objetividade é inconsciente, e que seria impossível o historiador ser objetivo, abstrair suas concepções ao passo que a imparcialidade exige do historiador honestidade e esta é conquistada através de revisões do trabalho histórico e acumulações de verdades parciais. Acreditamos que a mesma ideia se justapõe aos museus históricos e, portanto, pretendemos seguir uma análise ciente das relações entre objetividade e subjetividade na construção de uma narrativa museológica.

Nesse sentido, o entendimento sobre monumentos, materiais da memória, seriam heranças do passado, enquanto os documentos uma escolha do historiador (LE GOFF, 2013, p. 485). "O monumento tem como característica a perpetuação, voluntária ou involuntária, das sociedades históricas (é um legado para a memória coletiva)" (LE GOFF, 2013, p. 486). O documento para a escola positivista é o alicerce do fato histórico, e parece apresentar-se por si mesmo como prova histórica (LE GOFF, 2013, p. 486). $\mathrm{O}$ monumento teria uma intencionalidade que não corresponderia à objetividade do documento. Entretanto, a partir da chamada Escola dos Annales há uma ampliação do conceito de documento, bem como manifesta-se o entendimento de que não existe um documento objetivo e inócuo. "O documento não é qualquer coisa que fica por conta do passado, é um produto da sociedade que o fabricou segundo as relações de forças que aí detinham o poder" (LE GOFF, 2013, p. 495). Ambos são tomados de intencionalidade e de subjetividade.

Le Goff afirma que o documento é monumento. Resulta do esforço das sociedades históricas para impor ao futuro - voluntaria ou involuntariamente - determinada imagem de si próprias. No limite, não existe um documento-verdade (LE GOFF, 2013, p. 497). Posto isso, devemos expor que há uma pesquisa em andamento e, portanto, o objetivo do texto é provocar a reflexão, deste modo, concluímos afirmando que o objetivo não é construir um juízo de valor a respeito da trajetória do Museu do Tropeiro, mas auxiliar a instituição, bem como outras instituição que se dedicam à preservação do patrimônio cultural, caminhos e subsídios para que possam de alguma maneira possibilitar à sociedade o acesso à cultura, ao conhecimento da sua história, ao reconhecimento de possíveis laços indenitários e, consequentemente, permitir a conquista da cidadania.

\section{REFERÊNCIAS}

ASSOCIAÇÃO DE AMIGOS DO MUSEU DO TROPEIRO. Judith. Castro: Gráfica Kugler. 2013.

\section{BALHANA, A. P.; MACHADO, B. P. Campos Gerais: estruturas agrárias. Guritiba: UFPR, 1968.}

BORBA, O. B. Os iapoenses. 2. ed. Curitiba: LíteroTécnica, 1986

BRASIL. Decreto-Lei n ${ }^{\circ} 25$, de 30 de novembro de 1937. Organiza a proteção do patrimônio histórico e artístico nacional. Diбrio Oficial da Uniro, Brasília, DF, 1937. Disponível em: https://bityli.com/MupW8. Acesso em: 1 abr. 2019.

BRASIL. Lei ${ }^{\circ} 11.904$ de 14 de janeiro de 2009. Estabelece o Estatuto dos Museus. Dírio Oficial da Uniro, Brasília, DF, 2009. Disponível em: https://bityli.com/ PyJAx. Acesso em: 1 abr. 2019.

CANCLINI, N. G. Culturas híbridas: estratégias para entrar e sair da modernidade. São Paulo: Edusp, 2011.

CHOAY, F. A alegoria do patrimqnio. 6. ed. São Paulo: Estação Liberdade, 2017.

FONSECA, M. C. L. O patrimpnio em processo: trajetória da política federal de preservação no Brasil. 4. ed. Rio de Janeiro: Editora UFRJ, 2017.

GONÇALVES, J. R. S. Antropologia dos objetos: coleções, museus e patrimônio. Rio de Janeiro: Departamento de Museus e Centro Gulturais, 2007.

GOULART, J. A. Tropas e tropeiros na formazro do Brasil. Rio de Janeiro: Conquista, 1961.

HOLANDA, S. B. Caminhos e fronteiras. Rio de Janeiro: José Olympio, 1975. 
HORTA, M. L. P. Teatro da memória. Revista do Patrimфnio Histyrico e Arthstico Nacional, Rio de Janeiro, n. 22, p. 158-162, 1987

LE GOFF, J. Histyria e memyria. Campinas: Editora da Unicamp, 2013.

MAACK, R. Geografia fusica do estado do Paranб. Rio de Janeiro: José Olympio, 1981.

MACHADO, A. M. A. Cultura, ciência e política: olhares sobre a história da criação dos museus no Brasil. In: FIGUEIREDO, B. G.; VIDAL, D. G. (org.). Museus: dos gabinetes de curiosidade à museologia moderna. 2. ed. Belo Horizonte: Fino Trato, 2013. p. 145-157.

MENESES, U. T. B. A exposição museológica e o conhecimento histórico. In: FIGUEIREDO, B. G.; VIDAL, D. G. (org.). Museus: dos gabinetes de curiosidade à museologia moderna. Belo Horizonte: Argvmentvm, 2013. p. 15- 84.

MUSEU DO TROPEIRO. Ata de inaugurazro realizada no dia 21 de janeiro de 1977. Castro: Museu do Tropeiro, 1977. p. 1-2.
MUSEU DO TROPEIRO. Boletim informativo.

Castro: Museu do Tropeiro, 1980.

POMIAN, K. Colecção. In: POMIAN, K. Enciclopŭdia

Einaudi. Lisboa: Imprensa Nacional/Casa da Moeda, 1984. p. 51-86.

POULOT, D. Museu e museologia. Tradução de Guilherme João de Freitas Teixeira. Belo Horizonte: Autêntica, 2013.

ROMAGUERA NETTO, L. Erro histyrico \& outros ensaios. Curitiba: Impressora Oficial, 2002.

ROSAS, J. P. N. A fundazro da cidade de Castro. Curitiba: Vicentina, 1972.

SAINT-HILAIRE, A. Viagem pela Comarca de Curitiba. Guritiba: Fundação Cultural, 1995.

WESTPHALEN, C. M. O Barro dos Campos Gerais е о comŭrcio de tropas. Curitiba: CD Editora, 1995. 